\title{
Prevalence of tumors in domestic and exotic animals in Lower Silesia between 2012 and 2013
}

\author{
RAFAŁ CIAPUTA, JANUSZ MADEJ, PATRYK ŁAGODZKI*, JOANNA PAKUŁA*, \\ MAŁGORZATA KANDEFER-GOLA, IZABELA JANUS, STANIS $Ł A W$ DZIMIRA, \\ MARCIN NOWAK
}

\begin{abstract}
Department of Pathology, *Student Research Group of Anathomopathologists, Faculty of Veterinary Medicine, Wroclaw University of Environmental and Life Sciences, C.K. Norwida 31, 50-375 Wrocław
\end{abstract}

Ciaputa R., Madej J., Łagodzki P., Pakuła J., Kandefer-Gola M., Janus I., Dzimira S., Nowak M. Prevalence of tumors in domestic and exotic animals in Lower Silesia between 2012 and 2013

\section{Summary}

The aim of the study was to analyze the frequency and location of tumors in domestic as well as exotic animals in Lower Silesia. The research material consisted of $\mathbf{4 1 7 4}$ cases of malignancies from dogs, cats, horses and exotic animals taken at the time of surgery or biopsy sections. The largest group consisted of tumors of dogs 3519 cases $(84.31 \%)$, followed by cat -498 cases $(11.93 \%)$, ferrets -27 cases $(0.65 \%)$, rats -24 cases $(0.57 \%)$, horses -12 cases $(0.28 \%)$, rabbits -21 cases $(0.5 \%)$, guinea pigs, $21(0.5 \%)$. The average annual number of tests performed (2087 cases per year) may suggest an increased awareness of the need for veterinarians' testing for histopathology, whose purpose is to determine the prognosis of their patients, as well as the further proceedings. Tumors were divided into 6 histological types. The largest group were malignant epithelial and mesenchymal. It can be concluded that in domestic animals cancer most often occurs in carnivores, $60 \%$ of the cases considered as malignant tumors, and $40 \%$ benign (dogs), and correspondingly in cats $(76 \%$ and $24 \%)$ equally in both sexes in dogs and $20 \%$ prevalence of disease in male cats. In contrast, among the 146 reported cases referred to by us as exotic, cancer accounted for $59.6 \%$ and $40.4 \%$ benign.

Keywords: domestic animals, tumors, Lower Silesia, Poland

Carcinogenesis is a multistage molecular process leading to nonlethal damage of the cell genome. Genetic damage may affect protooncogenes, neoplastic tumor suppressor genes (anti-oncogenes), genes regulating apoptosis and DNA repair genes. They may be damaged as a result of exogenous or spontaneous mutations, occurring at a rate of $10^{-6}-10^{-7}$ mutations/ gene/cell division (1). A high malignancy phenotype occurs as a result of self-sufficiency in growth signals, decreasing sensitivity to growth-inhibitory signals, avoidance of apoptosis, angiogenesis and metastasis (6). The latter factors determine the outcome and impact survivability, usually leading to the patient's death. Hence, the sooner a malignant tumor is detected, the greater the chance of a successful treatment. Patients can then be classified into groups depending on the risk of recurrence. Screening and epidemiological studies in humans are also useful in determining carcinogenesis, and there are few similar studies in veterinary medicine. The aim of this study was to present epidemiological data concerning carcionegenesis obtained from a large group of domestic animals.

\section{Material and methods}

The study was carried out on 4174 tumor sections from dogs, cats, horses and exotic animals in Lower Silesia collected during surgery, a post-mortem examination or biopsy, which were sent to the Department of Pathology for a histopathological analysis. The sections were fixed in 7\% buffered formalin, dehydrated, and paraffin-embedded. The sections were routinely stained using H\&E. If this staining gave inconclusive results, the sections were stained with van Gieson's and Masson's trichrome and toludine blue stains. Immunohistochemistry was used in some cases. The tumors were divided into six histological types: 1 embryonal, 2 - organ primordia, 3 - epithelial, 4 - nervous and chromogenic tissue, 5 - mesenchymal and mesoderm, 6 - composite.

\section{Results and discussion}

4174 tumors were detected in animals in Lower Silesia between 2012 and 2013, indicating 2087 cases per year. Studies conducted in the same area between 1957 and 1967 reported an average of 33 cases per year (5), while 23 tumors per year were reported between 
1976 and 1995 (9). We carried out and published studies assessing the incidence of tumors in Lower Silesia between 2000 and 2004 and found a mean of 192 cases of tumors per year (11), and 488 cases per year between 2005 and 2008 (10). Ciaputa et al. recorded 1404 tumors per year in Lower Silesia between 2009 and 2011. These results indicate there is a constant incidence of tumors in animals in Lower Silesia. There is growing awareness among veterinarian and pet owners concerning the importance of a histopathological diagnosis in the choice of therapy and determination of the prognosis for the tumor.

In the present study, canine tumors comprised the largest group - 3519 cases $(84.31 \%)$, followed by feline tumors -498 cases $(11.93 \%)$, tumors in ferrets -27 cases $(0.65 \%)$, rats -24 cases $(0.57 \%)$, horses 12 cases $(0.28 \%)$, rabbits -21 cases $(0.5 \%)$, guinea pigs -21 cases $(0.5 \%)$, hamsters - five cases $(0.12 \%)$, parrots - three cases, bearded lizards - two cases, porcupines - two cases. There were single cases of tumors in a gopher, chinchilla, chameleon, goat, iguana, lion, mouse, gerbil and 29 other species.

Of the 3519 tumors found in dogs, 60.81 (2140 cases) were malignant and $39.19 \%$ (1379 cases) were benign. The majority of the tumors in dogs (1731 cases, 49.2\%) were mesodermal and mesenchymal. There were 1699 cases (48.28\%) of epithelial tumors, 128 cases of composite tumors $(3.64 \%)$, five tumors $(0.15 \%)$ of the nervous tissue and $151(4.29 \%)$ testicular and ovarian tumors (Fig. 1).

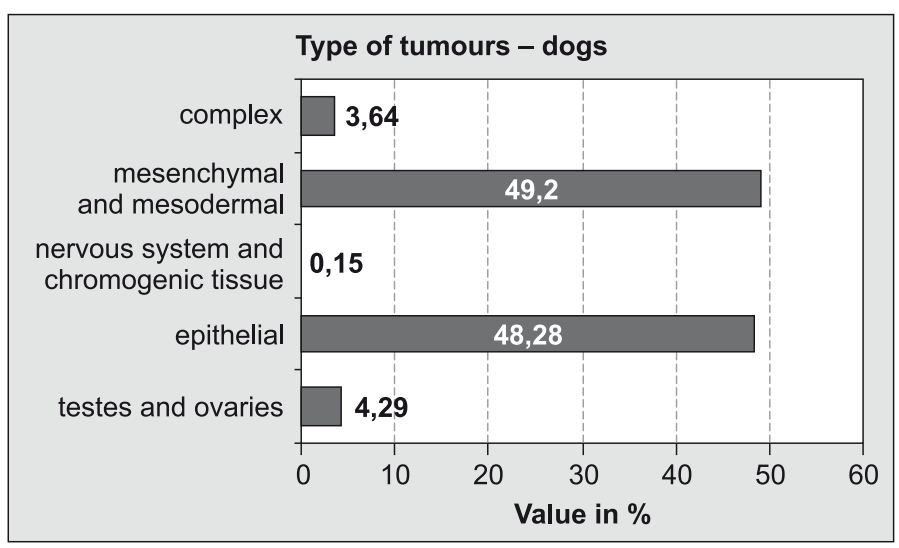

Fig. 1. Types of tumours in dogs

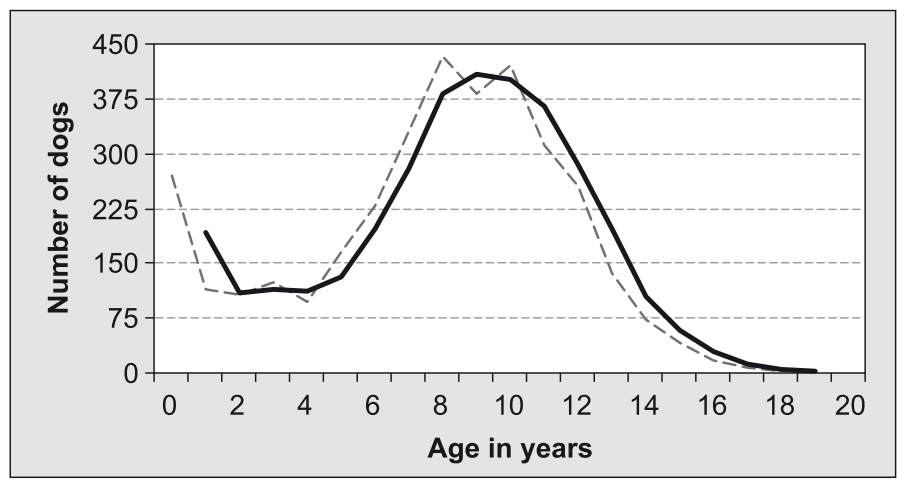

Fig. 2. Tumours in dogs with relation to age
There was a similar percentage of affected males 1642 cases $(46.7 \%)$ and females - 1876 cases $(53.3 \%)$. The occurrence of neoplasia depending on the gender and age in dogs is presented in Fig. 2. A marked increase in the incidence of neoplasia was noted in animals of both genders older than two years, with a peak between seven and eleven years. In the study carried out in the $1950 \mathrm{~s} / 60 \mathrm{~s}$, the authors found the highest incidence of neoplasia in animal populations between 10 and 12-years-old (5). In our studies carried out between 2000-2004 (11) and 2005-2008 (10), we found the highest incidence of neoplasia in animals between eight and nine-years-old. In Lower Silesia, tumors were found in $4.3 \%$ of dogs younger than two years between 1957-1967 (3), in 4.8\% of dogs between 1976-1995 (9), and in less than $4.3 \%$ of animals between 2000-2004 (11). A twofold increase in the number of young dogs diagnosed with tumors $(8.2 \%)$ was recorded between 2005 and 2008. That finding was also confirmed in a study carried out between 2009 and 2011 (10). We found that the incidence of neoplasia in dogs younger than two years amounted to $6.28 \%$.

The highest incidence of neoplasia was reported in mixed-breed dogs - 1049 (29.8\%). Among purebred dogs, German Shepherds had the highest tumor incidence -256 cases $(7.2 \%)$, followed by Boxers - 237 cases $(6.7 \%)$, Labrador Retrievers - 218 cases $(6.1 \%)$, Yorkshire Terriers -159 cases $(4.5 \%)$, Dachshunds - 146 cases (4.1\%), Golden Retrievers - 132 cases (3.7\%), American Staffordshire Terriers - 105 cases $(2.9 \%)$, Miniature Schnauzers -87 cases (2.4\%), Cocker Spaniels - 86 cases (2.4\%), Siberian Huskies -77 cases $(2.1 \%)$, Beagles -57 cases $(1.6 \%)$, Bernese Mountain Dogs - 51 cases $(1,4 \%)$, French Bulldogs -49 cases (1.3\%), Shih-tzu dogs - $48(1,3 \%)$, Dobermans -44 cases $(1.2 \%)$, West Highland White Terriers - 42 cases (1.2\%), Standard Schnauzers - 39 $(1.1 \%)$ and Rottweilers -35 cases $(1 \%)$. In the remaining breeds, the incidence did not exceed $1 \%$ of all the studied dogs (Tab. 1). The high incidence of tumors in mixed-breed dogs is in accordance with the results of previous studies. Mixed-breed dogs constituted 35.7\% of all dogs with neoplasia in the study by Michalska (9), $27 \%$ in the study of Malicki (7) and 36\% in our study carried out between 2000 and 2004 (11), 31.7\% according to our study between 2005 and 2008 (10), and $30.1 \%$ according to our findings between 2009 and 2011 (2). The incidence of tumors in a given breed depends on the popularity of that breed at a given time point. Hence, a high incidence of tumors was found in the Yorkshire terrier and more than $1 \%$ of the tumors were reported in small breeds such as the French Bulldog and Shih-tzu. Our results may also indicate that owners choose purebred dogs rather than mixedbreed dogs, or that purebred dogs are more predisposed to neoplasia than mixed-breed dogs.

The majority of the tumors were located in the skin or subcutaneous tissue - 1506 cases, which amounted 
Tab. 1. Tumours in individual breeds of dogs

\begin{tabular}{|c|c|c|c|}
\hline Breed & $\begin{array}{c}\text { Number (\%) } \\
\text { of animals }\end{array}$ & Breed & $\begin{array}{c}\text { Number (\%) } \\
\text { of animals }\end{array}$ \\
\hline Mixed-breed & $1049(29.8)$ & Dogo Argentino & $9(0.2)$ \\
\hline German Shepherd & 256 (7.2) & Belgian Shepherd & $9(0.2)$ \\
\hline Boxer & $237(6.7)$ & Polish Hunting Dog & $9(0.2)$ \\
\hline Labrador Retriever & $218(6.1)$ & Polish Tatra Sheepdog & $8(0.2)$ \\
\hline Yorkshire Terrier & $159(4.5)$ & Dog de Bordeaux & $8(0.2)$ \\
\hline Dachsund & $146(4.1)$ & Leonberger & $8(0.2)$ \\
\hline Golden Retriever & $132(3.7)$ & Staffordshire Bull Terrier & $7(0.2)$ \\
\hline American Staffordshire Terrier & $105(2.9)$ & Collie Sheepdog & $6(0.2)$ \\
\hline Miniature Shnaucer & $87(2.4)$ & Newfoundland & $6(0.2)$ \\
\hline Cocker Spaniel & $86(2.4)$ & Chow Chow & $6(0.2)$ \\
\hline Siberian Husky & $77(2.1)$ & Caucasian Shepherd & $6(0.2)$ \\
\hline Beagle & 57 (1.6) & Powderpuff & $6(0.2)$ \\
\hline Bernese Mountain Dog & 51 & Central Asian Sheepdog & $5(0.1)$ \\
\hline French Bulldog & $49(1.3)$ & Maltese & $5(0.1)$ \\
\hline Shih-tzu & 48 (1.3) & Standard Poodle & $5(0.1)$ \\
\hline Doberman & $44(1.2)$ & Springer Spaniel & $5(0.1)$ \\
\hline West Highland White Terrier & $42(1.2)$ & Border Collie & $5(0.1)$ \\
\hline Standard Sznaucer & $39(1.1)$ & Bichon Maltaise & $5(0.1)$ \\
\hline Rottweiler & $35(1.0)$ & Samoyed & $5(0.1)$ \\
\hline Foxterrier & $29(0.8)$ & Tibetan Mastiff & $4 \quad(0.1)$ \\
\hline Bavarian Mountain Hound & $22(0.7)$ & English Buldog & $4 \quad(0.1)$ \\
\hline Bullterrier & $20(0.6)$ & Flat Coated Retriever & $4(0.1)$ \\
\hline Irish Setter & $19(0.6)$ & Pekingese & $4(0.1)$ \\
\hline Weimaraner & $19(0.6)$ & Akita Inu & $4(0.1)$ \\
\hline Alaskan Malamute & $19(0.6)$ & Boston Terrier & $4 \quad(0.1)$ \\
\hline Miniature Poodle & $18(0.6)$ & Basset & $4(0.1)$ \\
\hline Great Dane & $17(0.5)$ & Shetland Sheepdog & $4(0.1)$ \\
\hline St. Bernard & $16(0.5)$ & Greater Swiss Mountain Dog & $4(0.1)$ \\
\hline Rhodesian Ridgeback & $16(0.5)$ & Whippet & $4(0.1)$ \\
\hline Giant Schnauzer & $15(0.4)$ & Ponny & $4(0.1)$ \\
\hline Black Russian Terrier & $15(0.4)$ & Miniature Pinscher & $3(0.08)$ \\
\hline Dalmatian & $15(0.4)$ & Cavalier King Charles Spaniel & $3(0.08)$ \\
\hline German Pointer & $14(0.4)$ & Hovawart & $3(0.08)$ \\
\hline Standard Poodle & $14(0.4)$ & German Spaniel & $3(0.08)$ \\
\hline Cane Corso & $14(0.4)$ & Gordon Setter & $3(0.08)$ \\
\hline Briard & $13(0.3)$ & Kerry Blue Terrier & $3(0.08)$ \\
\hline Shar-pei & $12(0.3)$ & Bouvier des Flandres & $3(0.08)$ \\
\hline Welsh Terrier & $11(0.3)$ & English Setter & $3(0.08)$ \\
\hline Pug & $11(0.3)$ & Polish Lowland Sheepdog & $3(0.08)$ \\
\hline Scottish Terrier & $10(0.3)$ & Airedale Terrier & $3(0.08)$ \\
\hline Jack Russel Terrier & $10(0.3)$ & Rough Collie & $3(0.08)$ \\
\hline
\end{tabular}

\begin{tabular}{|c|c|}
\hline Breed & $\begin{array}{c}\text { Number (\%) } \\
\text { of animals }\end{array}$ \\
\hline Brussels Griffon & $2(0.05)$ \\
\hline American Akita & $2(0.05)$ \\
\hline Keeshond & $2(0.05)$ \\
\hline English Bulldog & $2(0.05)$ \\
\hline Tiberan Terrier & $2(0.05)$ \\
\hline Parson Russel Terrier & $2(0.05)$ \\
\hline German Pinscher & $2(0.05)$ \\
\hline Tosa Inu & $2(0.05)$ \\
\hline Munsterlander & $1(0.02)$ \\
\hline Puli & $1(0.02)$ \\
\hline Ihasa Apso & $1(0.02)$ \\
\hline Gordon Setter & $1(0.02)$ \\
\hline Australian Cattle Dog & $1(0.02)$ \\
\hline Bullmastiff & $1(0.02)$ \\
\hline Chichuachua & $1(0.02)$ \\
\hline Polish Greyhound & $1(0.02)$ \\
\hline Fila Brasileiro & $1(0.02)$ \\
\hline Polish Hound & $1(0.02)$ \\
\hline Vizsla & $1(0.02)$ \\
\hline Flat Coated Retriever & $1(0.02)$ \\
\hline Borzoi & $1(0.02)$ \\
\hline Black Russian Terrier & $1(0.02)$ \\
\hline Perro de Presa Canario & $1(0.02)$ \\
\hline Moscow Watchdog & $1(0.02)$ \\
\hline Kerry Blue Terrier & $1(0.02)$ \\
\hline Italian Greyhound & $1(0.02)$ \\
\hline Bobtail & $1(0.02)$ \\
\hline Bolognese & $1(0.02)$ \\
\hline Neapolitan Mastiff & $1(0.02)$ \\
\hline Silky Terrier & $1(0.02)$ \\
\hline Jagdterrier & $1(0.02)$ \\
\hline Swiss Shepherd & $1(0.02)$ \\
\hline Waterhound & $1(0.02)$ \\
\hline Welsh Corgi & $1(0.02)$ \\
\hline Entelbucher & $1(0.02)$ \\
\hline Bedlington Terrier & $1(0.02)$ \\
\hline Italian Pointing Dog & $1(0.02)$ \\
\hline English Staffordshire Terrier & $1(0.02)$ \\
\hline Bloodhound & $1(0.02)$ \\
\hline Afghan hound & $1(0.02)$ \\
\hline
\end{tabular}


to $42.79 \%$ of all the tumors in dogs. Tumors of the mammary gland constituted the second largest group $-640(18.19 \%)$, followed by tumors of the lymphatic system $-210(5.97 \%)$ and gastrointestinal tract -233 $(6.62 \%)$. The prevalence of tumors in other organs did not exceed $4 \%$.

Most of the tumors in the skin and subcutaneous tissue were derived from histiocytes - 200 cases $(13.28 \%)$ and mast cells $-212(14 \%)$. The remaining tumors located in the skin and subcutaneous tissue were lipomas - $192(12.75 \%)$, adenomas - $125(8.3 \%)$, non-keratinizing squamous cell carcinomas -108 (7.17\%), keratinising squamous cell carcinomas -65 (4.32\%), adenocarcinomas - 83 (5.5\%), fibrosarcomas - $76(5.05 \%)$, basal cell carcinomas - $53(3.52 \%)$, fibromas $-42(2.79 \%)$, pleomorphic sarcomas -16 $(1.06 \%)$, malignant melanomas - 43 (2.85\%), simple hemangiomas - $18(1.19 \%)$ and skin lymphomas - 23 $(1.53 \%)$. The prevalence of the remaining tumors did not exceed $2 \%$.

The second most common type of tumour in dogs was located in the mammary gland, and included adenocarcinomas - 449 cases, which comprised $70.15 \%$ of all the mammary tumours. Adenomas -50 (7.81\%), mixed tumours - $69(10.78 \%)$, carcinomas $-15(2.34 \%)$, fibrosarcomas - $11(1.71 \%)$, lipomas $12(1.87 \%)$ and fibromas $-4(0.62 \%)$ were diagnosed much less commonly. The incidence of the remaining tumours did not exceed $1 \%$.

Tumors also commonly affected the lymphatic system. Most tumors were found in lymph nodes -210 cases, which constituted $70.7 \%$ of all the tumors. $89 \%$ of those tumors were lymphomas. 78 tumors $(26.3 \%)$ were found in the spleen. The majority of those tumors were lymphomas $-32 \%$, angiosarcomas $-25(32 \%)$, cavernous hemangiomas - $1(1.3 \%)$, simple hemangiomas $(5.1 \%)$ and fibrosarcomas (3.8\%). Pleomorphic sarcomas constituted $5.3 \%$ cases. The incidence of the remaining tumors did not exceed $1 \%$.

The gastrointestinal tract and liver were the fourth most common tumor location. The majority of the tumors were located around the oral cavity -241 (55.5\%), and included fibrous epulides - $48(19.9 \%)$, histiocytomas $30(12.4 \%)$, papillomas - $12(5 \%)$, nonkeratinizing squamous cell carcinomas - 31 (12.9\%), fibrosarcomas - 19 (7.9\%), melanomas - 19 (7.9\%) and fibromas $-5(2.1 \%) .32$ tumors were located in the intestine, which constituted $13.3 \%$ of all the tumors in the gastrointestinal tract. Eleven of those cases were lymphomas (34.4\%). There were 119 tumors of the rectum or anal glands, which constituted $49 \%$ of all the tumors in the gastrointestinal tract. Most of those tumors were adenomas (73 cases), and adenocarcinomas (34 cases). 1.2\% tumors were located in the stomach, and included carcinomas and fibrosarcomas. $6 \%$ of the tumors of the gastrointestinal tract were located in the liver (14 cases). Nine of those tumors were liver and bile duct carcinomas (64.3\%). Hepatic adenomas and adenomcarcinomas were also found. Neoplastic cells were diagnosed in aspiration fluid from the abdominal cavity collected from four patients, and included a carcinoma, adenocarcinoma and a mesothelioma.

There were 134 cases of tumors in the male reproductive system. This constituted $3.8 \%$ of all the canine tumors and $8.2 \%$ of the tumors in males. Most of those tumors were located in the testes $-6.1 \%$ of the tumors in males. The most common tumors included the Leydig cell tumor $-42 \%$, seminoma $-34 \%$, Sertoli cell tumor $-20.0 \%$ and simple hemangioma $-1 \%$. Prostatic tumors made up $0.9 \%$ of all the tumors in males, and $10.4 \%$ of the tumors of the male reproductive system.

There were 43 tumors in the female reproductive system, which constituted $1.2 \%$ of all the tumors in dogs and $2.3 \%$ of the tumors in females. Most of the tumors were localized in the vagina $(44.2 \%$ of the tumors of the female reproductive system) and included leiomyomas $-57.9 \%$, fibromas, fibrosarcomas, simple hemangiomas and adenocarcinomas. $32.5 \%$ of the tumors were localized in the uterus and consisted mainly of leiomyomas. $23.3 \%$ of the tumors were in the ovaries and included folliculomas and carcinomas.

There were 47 skeletal tumors, which constituted $1.33 \%$ of all the tumors in dogs. The most commonly diagnosed tumors were osteosarcomas $-40.4 \%$, osteomas $-19.1 \%$, fibrosarcomas $-8.5 \%$ and chondromas $-6.4 \%$.

There were 30 cases of tumors within the urinary tract, which was $0.1 \%$ of all the tumors in dogs. Most of the tumors were localized in the urinary bladder $63.3 \%$, and mainly consisted of a bladder carcinoma $-31.6 \%$ and papilloma $-15.8 \%$. The other tumors included myomas, lymphomas, adenomas, adenosarcomas, hemangiosarcomas and transitional cell carcinomas. Renal tumors (mainly renal carcinomas) composed $26.7 \%$ of all urinary tract tumors. There were two carcinomas and one fibroma in the urethra.

33 tumors $(0.9 \%$ of all canine tumors) were located in the respiratory tract. The most common tumor localization was the nasal cavity $-84.8 \%$ (adenocarcinoma, adenoma, melanoma, histiocytoma, keratinising squamous cell carcinoma and osteosarcoma). There were five cases of lung tumors, including carcinoma, chondrosarcoma and hemangiopericytoma.

Thyroid tumors in dogs appeared rarely $-0.4 \%$ of all tumors, and included adenocarcinomas, adenomas and carcinomas. There were 100 tumors of the ear, comprising $2.8 \%$ of all the tumors in dogs (adenomas $8 \%$, adenocarcinomas $-11 \%$, basal cell carcinomas $-8 \%$, histiocytomas $-20 \%$ and non-keratinising squamous cell carcinomas $24 \%$; the remaining tumors did not exceed $8 \%$ ). There were only $0.14 \%$ tumors of the musculoskeletal system (fibrosarcoma, lipoma and pleomorphic sarcoma). The eyeball (7 cases, $0.2 \%$, including melanoma, carcinoma, sarcoma and 
fibrosarcoma) and bone marrow (8 cases of myeloid leukemia, $0.02 \%$ ) were the rarest tumor localizations.

Tumors diagnosed based on the analysis of the aspiration fluid from the thoracic or abdominal cavity and pericardium and tumors from the abdominal cavity comprised a separate group $(0.45 \%$ of all the tumors in dogs). The cytological analysis of the aspiration fluid revealed the presence of an adenocarcinoma and carcinoma in the abdominal and thoracic cavities and a hemangiosarcoma and endothelioma in the pericardium.

Feline tumors made up $11.9 \%$ of all the diagnosed tumors, indicating an almost six-fold increase in the incidence of neoplasia in cats compared to that from the $1960 \mathrm{~s}(2.1 \%)$ (5), an increase of one-third compared to the results obtained between 2000 and $2004-9 \%$ (11), a comparable value to the one obtained between 2005 and 2008 (10), and a slight decrease compared to the results from $2009-2011-12.6 \%$ (2). Of the 498 tumors in cats, $76.7 \%$ (382 cases) were malignant and $23.3 \%$ ( 116 cases) were benign. Epithelial tumors were the most common type of neoplasia, diagnosed in 281 cases $(56.4 \%)$. Mesenchymal and mesodermal tumors were diagnosed in 210 cases $(42.2 \%)$. The third most common type of tumor was the composite tumor, diagnosed in seven cases (1.4\%) (Fig. 3).

The incidence of tumors was higher in female cats than in female dogs (309 cases, which constituted $62 \%$ ). There were 189 cases of tumors in male cats $(38 \%)$. In total, 498 cases of feline tumors were recorded between 2012-2013. The correlation between the incidence of neoplasia and the gender and age of the patients is presented in Fig. 4. An increased incidence was observed in cats from 7 to 11-years-old, while the peak incidence was noted in animals from 9 to 11 -years-old. The number of young cats with neoplasia (under 2 years of age) did not exceed $6 \%$.

432 tumors were recorded in European shorthair cats $(86.7 \%$ of the whole studied feline population). In the remaining breeds, the highest tumor incidence was recorded in Persians $-21(4.2 \%)$, British -14 (2.8\%), Maine Coons - $11(2.2 \%)$ and in Norwegian Forest Cats $-8(1.6 \%)$. The incidence did not exceed $0.5 \%$ in the Devon Rex, Abyssinian, Exotic, Ragdoll, Russian Blue, Siberian, Siamese, Thai and Turkish Van Angora. Similarly to dogs, the high incidence of tumors in mixed-breed cats is associated with a predominance of mixed breed animals over pure bred cats in the entire feline population in Poland.

The majority of the tumors were located in the skin or subcutaneous tissue -210 cases $(42.2 \%$ of the entire studied feline population). Mammary tumors were the second most common type of tumor - 119 (23.9\%), followed

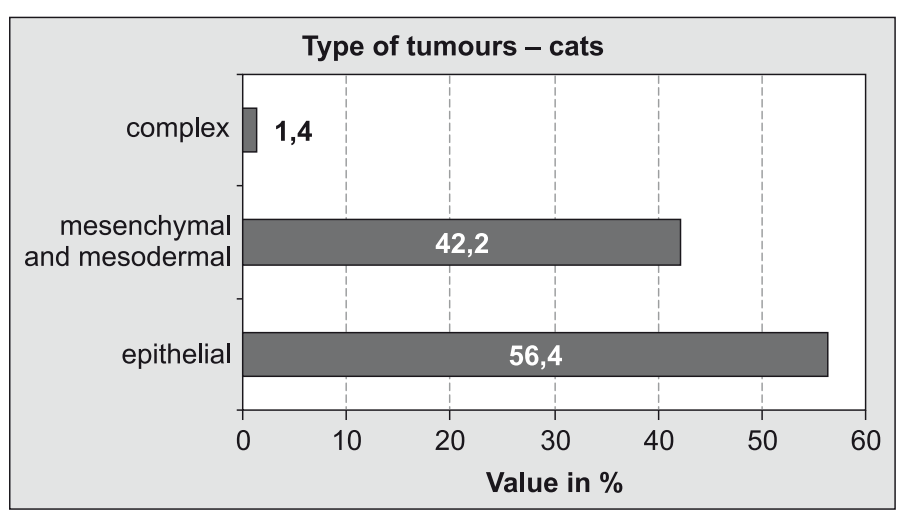

Fig. 3. Types of tumours in cats

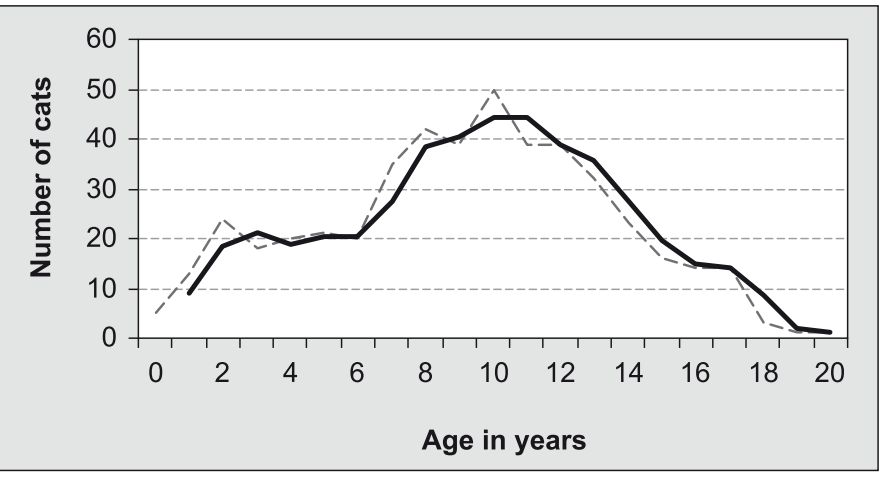

Fig. 4. Manifestation of tumours in cats as related to age

by tumors of the gastrointestinal tract and liver -53 $(25.2 \%)$ and the lymphatic system - $19(3.5 \%)$. The incidence in the remaining localizations did not exceed $2 \%$.

In the group of skin and subcutaneous tissue tumors, 56 cases $(26.6 \%)$ were fibrosarcomas, $14(6.6 \%)$ were non-keratinizing squamous cell carcinomas, 9 cases were adenomas $(4.3 \%), 16$ cases were lipomas $(7.6 \%)$, 20 cases were adenocarcinomas $(9.5 \%), 16$ were basal cell carcinomas $(7.6 \%)$ and 13 were carcinomas $(6.2 \%)$. The incidence of the remaining tumors did not exceed $5 \%$. Mammary tumors, particularly adenocarcinomas - 99 cases $(83.2 \%)$ were the second most common type of feline neoplasia. Adenomas comprised 6.7\%, fibrosarcomas $-1.2 \%$ and fibroadenomas $-2.5 \%$ of all the tumors in that localization. Other types of neoplasia were sporadically diagnosed in the mammary gland.

Tumors of the gastrointestinal tract were most commonly localized in the oral cavity $-30(56.6 \%$ of all

Tab. 2. Tumours in individual breeds of cats

\begin{tabular}{|l|r|l|r|}
\hline \multicolumn{1}{|c|}{ Breed } & Number (\%) of animals & \multicolumn{1}{c|}{ Breed } & Number (\%) of animals \\
\hline Mixed-breed & $432(86.7)$ & Russian Blue & $2(0.4)$ \\
Persian & $21(4.2)$ & Exotic & $1(0.2)$ \\
British & $14(2.8)$ & Ragdoll & $1(0.2)$ \\
Maine Coon & $11(2.2)$ & Abyssinian & $1(0.2)$ \\
Norwegian Forest Cat & $8(1.6)$ & Turkish van Angora & $1(0.2)$ \\
Siberian & $3(0.5)$ & Thai & $1(0.2)$ \\
Siamese & $2(0.4)$ & Devon Rex & $1(0.2)$ \\
\hline
\end{tabular}


the tumors) and the non-keratinizing squamous cell carcinoma predominated - $11(36.7 \%)$, followed by fibrous epulides - seven $(23.3 \%)$ and carcinomas - two $(6.7 \%)$. Of the intestinal tumors, four were found to be lymphomas, two were carcinomas, two were sarcomas, two were leiomyomosarcoma and one was a leyiomyosarcoma. In addition, a hepatic adenoma and bile duct carcinoma were recorded. 15 tumors were found in the lymphatic system. Lymphomas and metastatic cancer cells were found in lymph nodes. Tumors in the skeletal system were present as osteomas, osteosarcomas, fibrosarcomas and a fibro-osteosarcoma. There were single tumors in the remaining organs.

12 of all the studied tumors were obtained from horses $(0.2 \%)$. Six of those tumors were malignant $(50 \%)$ and six were benign (50\%). Epithelial tumors were the most common type of neoplasia $-50 \%$ ( 6 cases), followed by mesenchyme/mesoderm tumors $-25.5 \%$ ( 3 cases). The remaining tumors were derived from connective tissue. $50 \%$ of the tumors were from males, and 50\% were from females. The highest incidence was noted in the animals between 3 and 10-years-old, irrespective of gender. Most of the tumors were located in the skin and subcutaneous tissue $(83.3 \%)$ and included fibromas - three cases and a sarcoid and malignant melanoma - two cases. The remaining tumors were located in the oral cavity (papillomas).

We recorded 111 cases of tumors in exotic animals, which constituted $2.6 \%$ of all the studied tumors. Most of the tumors were found in ferrets (27 cases, 24.3\%), rats (24 cases, $21.6 \%$ ), miniature rabbits and guinea pigs (21 cases each, $18.9 \%$ ). The tumor incidence was lower than $5 \%$ in the remaining species.

In ferrets, most of the tumors, including adenocarcinomas, fibromas and fibrosarcomas, were localized in the skin and subcutaneous tissue (18 cases, 66.6\%). Single cases of a squamous cell carcinoma and keratinising squamous cell carcinoma were observed. In addition, four tumors were found in the lymphatic system (14.8\%). Those included lymphomas in the spleen, lymph nodes and uterus. Two cases of adenocarcinoma were found in the adrenal glands. The majority of the tumors in rats were also located in the skin and subcutaneous tissue. Skin tumors predominated in miniature rabbits, followed by lesions in the mammary gland and single cases of testicular, uterine, stomach and lymph node growths. In comparison to the data obtained between 2000 and 2004 (11), 2005 and 2008 (10) and in particular that from 2009-2011 (66 cases) (2), there was an almost two-fold increase in the incidence of tumors in the present study. This may indicate that exotic animals are becoming increasingly popular as pets, and there is improvement in their veterinary healthcare.

As opposed to humans, who mostly have epithelial skin tumors, animals usually have mesenchymal skin lesions, such as histiocytomas or mastocytomas (dogs) and fibrosarcomas (cats). In animals, mastocytomas are always malignant or benign neoplastic lesions, while in humans they may occur in the form of urticaria pigmentosa, which remits spontaneously. Mastocytomas in the form of tumors rarely occur in humans. Mast cells infiltrate internal organs in less than $10 \%$ of human patients. Pigmented nevi and malignant melanomas, currently classified as melanocarcinomas occur less frequently in animals than humans.

Gastrointestinal tumors are diagnosed much less frequently in animals than humans $(6.6 \%$ vs. $16 \%$, apart from cats $-25 \%$ ). Similarly, tumors of the urinary tract $(0.1 \%$ vs. $6 \%$, ) prostate gland $(<0.1 \%$ vs. $5.5 \%$ in Poland and $31 \%$ in the USA $)$ and brain $(<0.1 \%$ vs. $2.5 \%$ ) are less frequent in animals than humans (12). The cervical carcinoma (7.6\%), associated with human papilloma viruses (HPV), has not been diagnosed in animals (13).

The high percentage of malignant mesenchymal soft tissue tumors in animals is surprising. In humans, benign tumors are more common than malignant ones and malignant mesenchymal tumors comprise only $1 \%$ of all malignant tumors (13). Mechanical factors, such as post-operative and post-traumatic scarring, plastic and metal implants as well as vaccinations in cats, are thought to play a large role in their formation.

In summary, tumors were most often found in domestic carnivores. $60 \%$ of the tumors were malignant, and $40 \%$ were benign in dogs compared to $76 \%$ and $24 \%$ respectively, in cats. The incidence of neoplastic disease increases with age, which is a result of a dampened immune response, an accumulation of mutations or carcinogens. Contrary to humans, it is difficult to determine mortality by neoplasia in animals. Mixed-breed animals were affected most often, while the incidence of epithelial and mesenchymal tumors was comparable. In humans, there is a predominance of epithelial tumors, while in animals, malignant mesenchymal are the most common types of tumors, particularly those located in soft tissues and skin. The number of tumors of the mammary gland is constantly rising in female dogs and exceeds the incidence of this type of tumor in women. It was the second most common type of diagnosed tumor, and included adenocarcinomas -449 cases, which comprised $70.15 \%$ of all the diagnosed mammary tumors. These data are comparable or slightly higher than in previous years $(2,11,12)$.

In recent years, there has been a significant increase in the detection rate of tumors in exotic animals. We found 111 cases of such tumors, which constitutes $2.6 \%$ of all the studied animals. Between 2005 and 2008 , there were only 20 cases reported $(1.2 \%$ of the total analyzed population) (10). There were no recorded cases between 2000 and 2004 (11), and 80 cases $(1.9 \%$ of total population) were reported between 
2009 and 2011 (2). This increase in the incidence of tumors in exotic animals is likely to grow and is most likely associated with a rising number of animals used for breeding.

Gesek carried out a similar study and analyzed the incidence of tumors in domestic animals in Warmia and Mazury (3). Grüntzig (4) assessed the incidence of neoplasia in dogs in Switzerland (4), while Merlo studied the incidence of canine tumors in Italy (8). Hence, epidemiologic studies that provide data on the incidence of neoplastic diseases in animals in Poland may be applied to other countries. However, such data should be updated continuously.

Neoplasia may be prevented by understanding the environmental risk factors caused by carcinogens, including polycyclic aromatic hydrocarbons, asbestos fibers or radiation. The carcinogenicity of certain compounds may be determined based on epidemiological studies and by analyzing their properties in laboratory animals as well as through observational studies, similar to this one.

\section{References}

1. Brown T. A.: Genoms. Wiley-Liss, New York 1999.

2. Ciaputa R., Kandefer-Gola M., NowakM., Madej J. A.: Prevalence of tumours in domestic animals in the Lower Silesia (Poland) in 2009-2011. Bull. Vet. Inst. Pulawy 2013, 57, 53-59.
3. Gesek M., Rotkiewicz T., Otrocka-Domagała I., Paździor-Czapula K., Kozłowska A., Korzeniowska P., Grochowska, Welenc J.: Manifestation of tumours in domestic animals in Warmia and Mazury (Poland) between 2003 and 2011. Bull. Vet. Inst. Pulawy 2014, 58, 439-446.

4. Grüntzig K., Graf R., Boo G., Guscetti F., Hässig M., Axhausen K. W., Fabrikant S., Welle M., Meier D., Folkers G., Pospischil A.: Swiss Canine Cancer Registry 1955-2008: Occurrence of the Most Common Tumour Diagnoses and Influence of Age, Breed, Body Size, Sex and Neutering Status on Tumour Development. J. Comp. Pathol. 2016, Jul 9.

5. Houszka M., Kaszubkiewicz Cz.: Nowotwory zwierząt domowych. Med. Weter. 1969, 25, 6-10.

6. Kumar V., Cotram R. S., Robbins S. C.: Robbins Patologia. Elsevier Urban \&Partner, Wrocław 2014.

7. Malicka E., Piusiński W., Sendecka H., Bielecki W., Osińska B., LenartowiczKubart Z: Nowotwory psów stwierdzone w badaniach anatomopatologicznych w latach 1985-1993. Med. Weter. 1996, 52, 263-267.

8. Merlo D. F., Rossi L., Pellegrino C., Ceppi M., Cardellino U., Capurro C., Ratto A., Sambucco P. L., Sestito V., Tanara G., Bocchini V.: Cancer incidence in pet dogs: findings of the Animal Tumor Registry of Genoa, Italy. J. Vet. Intern. Med. 2008, 22, 976-984.

9. Michalska Z., Michalski Z.: Występowanie nowotworów u zwierząt domowych we Wrocławiu i na Dolnym Śląsku w latach 1976-1995. Med. Weter. 1997, 53, 263-267.

10. Nowak M., Madej J. A.: Prevalence of neoplasms in domestic animals in Lower Silesia between 2000 and 2004. Med. Weter. 2006, 62, 900-904.

11. Nowak M., Madej J. A., Ciaputa R., Poradowski D.: Manifestation of tumours in domestic animals in Lower Silesia in 2005-2008. Bull. Vet. Inst. Pulawy 2010, 54, 229-236.

12. Roses D. F.: Breast Cancer. Churchill Livingstone, Philadelphia 1999.

13. Stachura J., Domagała W.: Patologia znaczy słowo o chorobie. Tom II. Patologia narządowa. PAU, Kraków 2005.

Corresponding author: Dr. Rafal Ciaputa Ph.D., ul. C. K. Norwida 31, 50-375 Wroclaw, Poland; e-mail: rafal.ciaputa@up.wroc.pl 